CASE REPORT

\title{
Assessment of the "nearly normal" cervical spine radiograph: C2-C3 pseudosubluxation in an adult with whiplash injury
}

\author{
P Curtin, J McElwain
}

Emerg Med J 2005;22:907-908. doi: 10.1136/emj.2004.020115

C2-C3 pseudosubluxation is a well recognized normal anatomical variant in children and this physiological spondylolisthesis often makes the interpretation of paediatric cervical spine radiographs difficult. In direct contrast, this finding is rare in adults and has not been reported as a diagnostic difficulty following neck injury. We report a case of C2-C3 pseudosubluxation occurring in a 27 year old woman presenting with neck pain 1 week after a road traffic accident. Although there are effective radiological guidelines for cervical spine radiograph evaluation in children, there is no evidence that these can be applied to the adult cervical spine. Flexion and extension cervical spine views have limitations. In such cases, magnetic resonance imaging is required to definitively exclude pathological injury.

$\mathrm{N}$ eck pain following whiplash injury is a common presenting complaint in emergency departments, and clinicoradiological evaluation of the cervical spine (cervical spine) is often difficult. The incidence of missed injury ranges from $4 \%$ to $8 \%$ of cervical spine injuries, ${ }^{1-3}$ and failed or delayed diagnosis can cause potentially catastrophic sequelae. ${ }^{3}$ The lateral cervical spine radiograph has an overall diagnostic sensitivity of $74-86 \%$ for skeletal injuries, and increases to nearly $100 \%$ when anterior-posterior and open mouth odontoid views are added. ${ }^{4}$ In non-skeletal injuries, the lateral view is diagnostic in $97 \%$ of cases. ${ }^{3}$

Pseudosubluxation is a normal anatomical variant in which, because of ligamentous laxity, there is physiological misalignment and anterior slippage of the body of C2 on C3. It is found in up to one fifth of children under 16 years of age and is usually recognisable on plain radiographs. ${ }^{56}$ In adults, this type of anterolisthesis can be normal if $<3 \mathrm{~mm}$, but is a rare finding. ${ }^{3} 78$

In this report, we present a case where C2-C3 spondylolisthesis complicated cervical spine assessment following injury. We discuss the clinical management of such cases. Although there are effective radiological guidelines for children, ${ }^{56}$ there is no evidence that these can be applied to the adult cervical spine or that they obviate the need for further imaging to rule out pathological injury.

\section{CASE REPORT}

A 27 year old woman was referred to the hospital radiology department by her primary care physician for cervical spine radiographs. She complained of pain and stiffness in her neck and left shoulder 1 week following a road traffic accident. Another vehicle had driven into the back of her car while it was stationary, and shunted it into the back of the vehicle in front, causing severe damage to her car. She was the driver at the time, and had been wearing a seat restraint. She felt
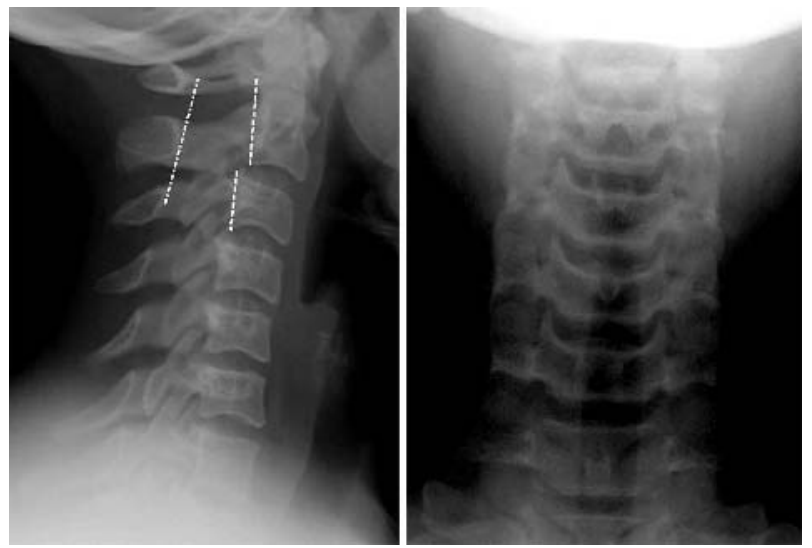

Figure 1 Lateral cervical spine radiograph showing anterolisthesis of $\mathrm{C} 2$ on $\mathrm{C} 3$, measuring $3 \mathrm{~mm}$. The posterior cervical line drawn from the cortex of the posterior arch of $\mathrm{Cl}$ to that of $\mathrm{C} 3$ lies $2 \mathrm{~mm}$ from the cortex of the posterior arch of $\mathrm{C} 2$.

physically well and did not seek medical advice until 5 days later when she developed stiffness and pain. Her symptoms failed to respond to anti-inflammatory medication. Cervical spine series showed a grade I spondylolisthesis of C2-C3 (fig 1), the only abnormal finding, upon which she was referred to the emergency department (ED) for further clinical assessment and orthopaedic review.

In the ED, the patient was treated as an acute cervical spine injury. Clinically she had left cervical paraspinal tenderness. There was no midline bony tenderness and no neurological deficit, and she could lift her head without pain. Review of her lateral cervical spine radiograph showed anterolisthesis of C2 on C3, measuring $3 \mathrm{~mm}$, and a significant loss of normal cervical lordosis indicating muscle spasm. There was no prevertebral swelling. Flexion and extension lateral cervical spine radiographic views (erect) were performed under orthopaedic supervision (fig 2). These were well tolerated by the patient, whose symptoms and neurological status remained unchanged.

MRI of the upper cervical spine ruled out disc or ligamentous injury (fig 3) and the patient was reassured, referred to the physiotherapist and discharged with appropriate analgesia.

\section{DISCUSSION}

Cervical spine radiographs are highly sensitive ${ }^{3}$ but not always specific. Accurate diagnosis is highly dependent upon observer experience. The presence or absence of prevertebral soft tissue swelling is not reliable in predicting or excluding

Abbreviation: $E D$, emergency department 

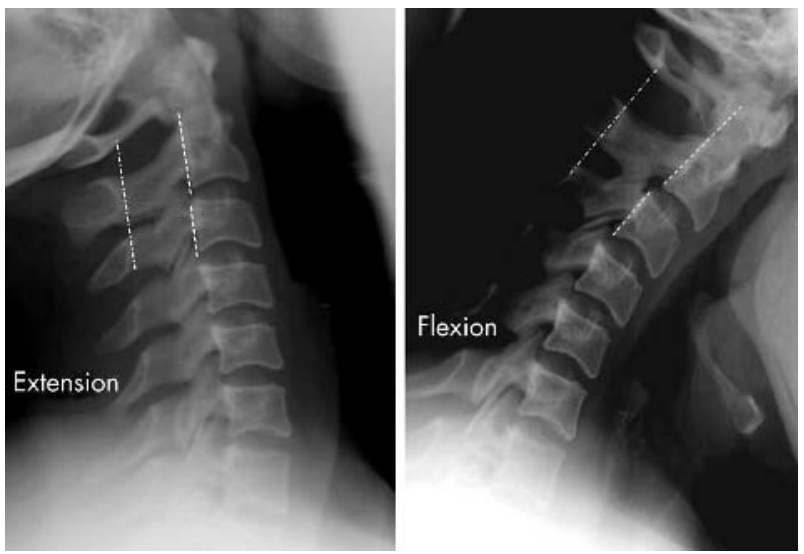

Figure 2 Extension lateral cervical spine radiograph showing normal alignment of the upper cervical spine. Flexion lateral cervical spine radiograph; the measurement of the deformity is the same as in fig 1 , with anterolisthesis of $\mathrm{C} 2$ on $\mathrm{C} 3$ of $3 \mathrm{~mm}$ and the posterior arch of $\mathrm{C} 2$ lies $2 \mathrm{~mm}$ from the posterior cervical line drawn from $\mathrm{Cl}$ to $\mathrm{C} 3$.

hidden bony or ligamentous injury, ${ }^{9-11}$ but a loss of alignment or subluxation between two contiguous vertebra usually indicates occult skeletal or non-skeletal injury. A pseudosubluxation or physiological anterolisthesis of C2 on C3 can also occur, and usually measures no more than $2 \mathrm{~mm}$. It is common in children, ${ }^{5}$ but in adults, has been reported at C2$\mathrm{C} 3$ or C3-C4 only as a rare incidental finding. ${ }^{8}$

In both children and adults, C2-C3 pseudosubluxation must be distinguished from a traumatic spondylolisthesis caused by a "hangman's fracture" (fracture of the pars interarticularis of C2). To aid diagnosis, Swischuk ${ }^{6}$ defined a posterior cervical line drawn between the anterior cortices of the posterior arches of $\mathrm{Cl}$ and $\mathrm{C} 3$. Swischuk examined and compared the radiographs of 26 children with physiological subluxation and eight children with traumatic spondylolisthesis. He found a major radiological difference between the two groups and suggested that if the anterior cortex of the posterior arch of C2 lay within $1.5 \mathrm{~mm}$ of the posterior cervical line, then a traumatic spondylolisthesis was unlikely. ${ }^{6}$ In adults, it is not known whether this observation applies. In this case, the difference was $2 \mathrm{~mm}$, but there was no pars fracture.

Biomechanical studies have shown that in upper cervical spine injury, a ligamentous injury is more likely when the mechanism is hyperflexion. ${ }^{12}$ The purpose of flexion and extension views is to assess the integrity of the posterior ligament complex. ${ }^{13}$ Flexion views in this case showed no measurable worsening of the spondylolisthesis and it appeared to resolve in extension. The value of normal flexion and extension radiographs in the acute setting when neck pain is present, is however, uncertain. ${ }^{14}$ We completed our investigations with a magnetic resonance image, which although expensive, is the definitive screening investigation for non-skeletal injury.

The incidence of missed injuries of the cervical spine is high, ${ }^{1-3}$ and failed or delayed diagnosis can cause potentially catastrophic sequelae. ${ }^{3}$ Abnormalities of the cervical spine, however subtle, should be evaluated definitively. From the patient's perspective, an accurate and early diagnosis should lead to better treatment and improved outcome, and also simplifies any future medicolegal issues.

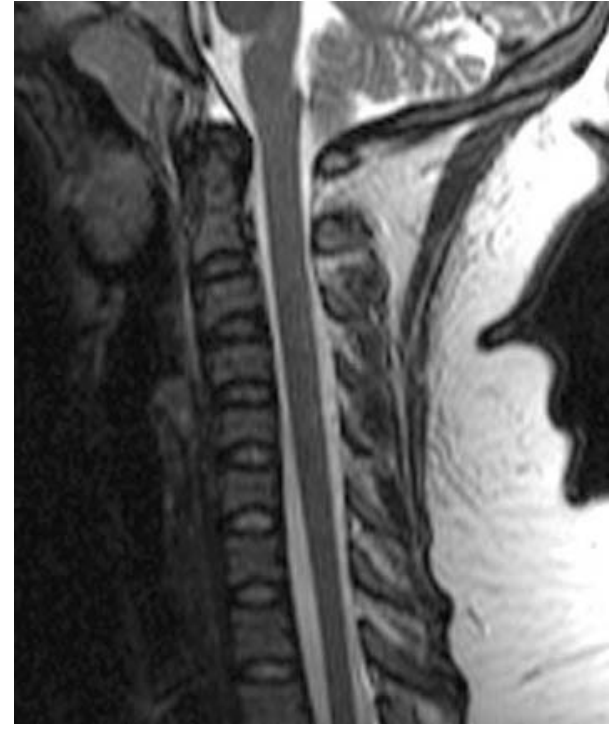

Figure 3 Sagittal T2 MRI images demonstrating the ligamentous integrity of the upper cervical spine.

\section{Authors' affiliations}

P Curtin, J McElwain, Department of Trauma and Orthopaedics, Adelaide and Meath incorporating the National Children's Hospital, Tallaght, Dublin 24, Republic of Ireland

Competing interests: none declared

Correspondence to: Dr P Curtin, Department of Trauma and Orthopaedics, AMNCH, Tallaght, Dublin 24, Republic of Ireland; pauldcurtin@hotmail.com

\section{Accepted for publication 19 October 2004}

\section{REFERENCES}

1 Demetriades D, Charalambides K, Chahwan S, et al. Nonskeletal cervical spine injuries: epidemiology and diagnostic piffalls. J Trauma 2000;48:724-7.

2 Poonnoose PM, Ravichandran G, McClelland MR. Missed and mismanaged injuries of the spinal cord. J Trauma 2002;53:314-20.

3 Davis JW, Phreaner DL, Hoyt DB, et al. The etiology of missed cervical spine injuries. J Trauma 1993;34:342-6.

4 Diliberti T, Lindsey RW. Evaluation of the cervical spine in the emergency setting: who does not need an X-ray? Orthopedics 1992;15:179-83.

5 Shaw M, Burnett $H$, Wilson A, et al. Pseudosubluxation of C2 on C3 in polytraumatized children - prevalence and significance. Clin Radiol 1999:54:377-80.

6 Swischuk LE. Anterior displacement of C2 in children: physiologic or pathologic? A helpful differentiating line. Pediatric Radiol 1977; 122:759-63.

7 Panjabi MM, White AA 3rd, Johnson RM. Cervical spine mechanics as a function of transection of components. J Biomech 1975;8:327-36.

8 Kopacz KJ, Connolly PJ. The prevalence of cervical spondylolisthesis. Orthopedics 1999;22:677-9.

9 Miles KA, Finlay D. Is prevertebral soft tissue swelling a useful sign in injury of the cervical spine? Injury 1988;19:177-9.

10 Templeton PA, Young JW, Mirvis SE, et al. The value of retropharyngeal soft tissue measurements in trauma of the adult cervical spine. Cervical spine soft tissue measurements. Skeletal Radiol 1987;16:98-104.

11 Herr CH, Ball PA, Sargent SK, et al. Sensitivity of prevertebral soft tissue measurement of $\mathrm{C} 3$ for detection of cervical spine fractures and dislocations. Am J Emerg Med 1998;16:346-9.

12 Nightingale RW, Winkelstein BA, Knaub KE, et al. Comparative strengths and structural properties of the upper and lower cervical spine in flexion and extension. J Biomech 2002;35:725-32.

13 Harris JH Jr. Missed cervical spinal cord injuries. J Trauma 2002;53:392-3.

14 Wang JC, Hatch JD, Sandhu HS, et al. Cervical flexion and extension radiographs in acutely injured patients. Clin Orthop 1999;365:111-16. 


\section{A case of familial third ventricular colloid cyst}

\section{S M Joshi, K K Gnanalingham, P Mohaghegh, A Wilson, A Elsmore}

Emerg Med J 2005;22:909-910. doi: 10.1136/emj.2004.018440

Colloid cyst of the third ventricle is a rare benign intracranial lesion, and familial cases are rarer still. They may be asymptomatic or present with symptoms of raised intracranial pressure, including sudden death. Surgical excision is curative. We report a 24 year old pregnant woman with familial colloid cyst, who presented with headaches and suffered a cardiorespiratory arrest. Early computed tomography scan of the brain is advised in patients with a family history of third ventricular colloid cyst presenting to the accident and emergency department with headache.

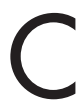
olloid cyst is a rare and benign intracranial lesion containing mucoid fluid, thought to arise from embryological remnants in the roof of the third ventricle. ${ }^{1-3}$ The usual age at diagnosis occurs within the second to fifth decades of life, with predilection in men. It is slow growing, eventually blocking the foramen of Monro and causing obstructive hydrochephalus. ${ }^{12}$ Colloid cysts may be asymptomatic, but symptoms can arise from raised intracranial pressure (ICP), secondary to obstructive hydrocephalus. ${ }^{12}$ Sudden death due to untreated hydrocephalus and raised ICP is well recognised in patients with colloid cyst. ${ }^{13}$

\section{CASE REPORT}

A 24 year old South Asian woman, who was 16 weeks pregnant, presented to the accident and emergency (A\&E) department, with a 2 day history of frontal headache and nausea associated with an episode of vomiting. She was neurologically intact, with no signs of meningism or raised intracranial pressure. The baseline heart rate was 72 beats/ min and systemic blood pressure was 100/65 mmHg. Her headaches improved with $1 \mathrm{~g}$ of paracetamol, following which she discharged herself from hospital.

At home, she continued to complain of intermittent headaches and 2 days later, she was found unconcious by her family, who were unable to rouse her. The ambulance service found her in a state of cardiorespiratory arrest (electromechanical dissociation), with bilaterally dilated and unreactive pupils. After cardiopulmonary resuscitation, cardiac output was regained, but she remained deeply unconscious, with no change in the pupillary state.

Family history revealed the sudden death of her mother and a maternal aunt at a young age, the cause of death being unclear in both cases. Of five siblings, one sister had died suddenly at the age of 21 years from a third ventricular colloid cyst, confirmed at postmortem examination.

An emergency computed tomography (CT) scan confirmed the presence of a hypodense third ventricular colloid cyst with acute hydrocephalus affecting the lateral ventricles (fig 1). Bilateral external ventricular drains were inserted as an emergency, releasing clear cerebrospinal fluid under raised pressure (30 $\mathrm{ml}$ of water). Postoperatively, there was no change in her neurological status and the pupils remained unchanged. She was declared dead after fulfilling brainstem criteria, 48 hours later. The family declined postmortem examination and any screening of the remaining family members.

\section{DISCUSSION}

Of patients presenting to the emergency department, 1.7\% describe headaches as the main symptom, and of these patients, $<15 \%$ have a secondary cause for headache. ${ }^{4}$ Colloid cyst of the third ventricle is a rare benign intracranial lesion, accounting for $<0.5 \%$ of brain tumours. ${ }^{1-3}$ Thus, it is an unusual cause of headache in the A\&E setting.

Colloid cysts can be entirely asymptomatic, with no clinical signs, and be discovered only incidentally. ${ }^{1-3}$ In symptomatic patients, headache $(68 \%)$, gait disturbance $(47 \%)$, and short term memory disturbances $(37 \%)$ are the most common symptoms, with papillo-oedema (47\%) and ataxia (32\%) the most common signs. ${ }^{1}$ Symptoms may be intermittent and are thought to be related to the movement of the colloid cyst on its pedicle from the roof of the third ventricle, causing episodic obstruction of the foramen of Monro, and intermittent intracranial hypertension. As in our case, sudden loss of consciousness or death from acute obstructive hydrocephalus and the resultant cerebellar herniation is a real risk. ${ }^{13}$ In the pre-CT era, changes in cerebrospinal fluid dynamics from procedures such as lumbar punctures may have contributed to the rate of sudden death reported in these patients. ${ }^{125}$

In the present case, the eventual diagnosis of obstructive hydrocephalus secondary to a hypodense third ventricular colloid cyst was made on CT imaging. Most colloid cysts are hyperdense on CT scans, although isodense and hypodense colloid cysts have also been noted. ${ }^{26-8}$ Colloid cysts rarely calcify and may show enhancement with contrast. Magnetic resonance (MR) imaging is a better imaging technique for these lesions, but occasionally, colloid cysts may be isosignal intensity on MR, and CT imaging may be more useful. ${ }^{8}$

The optimal treatment of colloid cysts is controversial. Early detection and total excision of the colloid cyst carries an excellent prognosis. ${ }^{2369}$ As in our patient, the acute hydrochephalus associated with the colloid cyst may require emergency drainage. Definitive treatment of colloid cysts is by surgical excision, through an open craniotomy (transcallosal or transcortical) or by endoscopy. ${ }^{2369}$ Stereotactic aspiration of the cyst contents has also been described, although there is a higher incidence of recurrence. ${ }^{269}$ The management of asymptomatic cases is influenced by the lesion size (usually surgical intervention when $>10 \mathrm{~mm}$ in diameter), the presence of hydrocephalus, and the patient's age, preference, and associated medical conditions. ${ }^{39}$

Familial cases of colloid cyst are extremely rare. ${ }^{5}{ }^{10-13}$ The age range is from $14-73$ years and there is a slight female predominance. Although our patient was pregnant at the time of presentation, this association has not been previously recognised. ${ }^{5}{ }^{10-13}$ Most patients identified with familial colloid cysts have been treated surgically, even when asymptomatic, although a few patients have been successfully managed

Abbreviations: $A \& E$, accident and emergency; $C T$, computed tomography; ICP, intracranial pressure; MR, magnetic resonance 

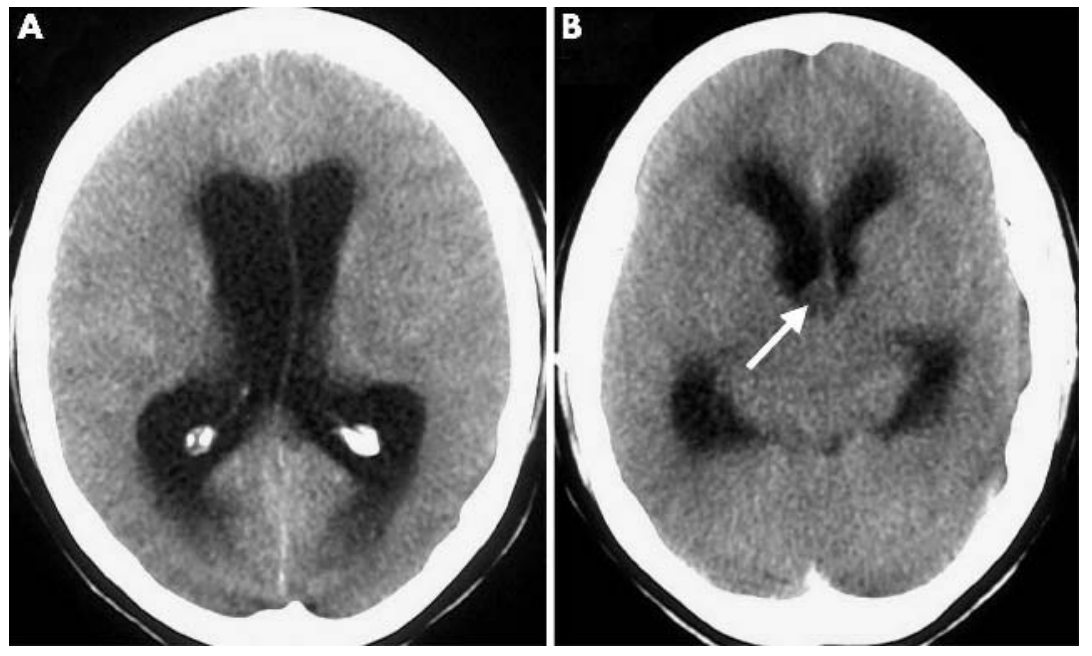

Figure 1 Pre-operative unenhanced CT scan of brain shows bilateral enlargement of the lateral ventricles (a) and a hypodense lesion (arrow) in the third ventricle (b).

conservatively with regular clinical and radiological follow up. $^{510-13}$

Genetic factors may play a role in the familial occurrence of this lesion, although specific chromosomal abnormalities are yet to be isolated..$^{10}$ The inheritance pattern is probably autosomal dominant, and there may be an association with other congenital defects. ${ }^{10-13}$ Screening is of value for families in which two or more members are affected. ${ }^{10-13}$

The present case emphasises the need for a low threshold for admission and investigation of headaches, in patients with a family history of colloid cysts; the consequence of missing this benign condition could be devastating.

\section{Authors' affiliations}

S M Joshi, K K Gnanalingham, P Mohaghegh, A Elsmore, Department of Neurosurgery, Royal London Hospital, Whitechapel Road, London, UK

A Wilson, Department of Accident and Emergency, Royal London Hospital, Whitechapel Road, London, UK

A Elsmore, Queen Mary University, University of London, Mile End, London, UK

Competing interests: none declared

Correspondence to: Mr K K Gnanalingham, 11 Deena Close, 'Brindhavan', Queen's Drive, London, W3 OHR, UK; kannagnana@ doctors.org.uk
Accepted for publication 22 December 2004

\section{REFERENCES}

1 Little JR, MacCarty CS. Colloid cysts of the third ventricle. J Neurosurg 1974;39:230-5.

2 Desaki KI, Nadkami TD, Muzumdar DP, et al. Surgical management of colloid cyst of the third ventricle - a study of 105 cases. Surg Neurol 2002;57:295-302.

3 Apuzzo MLJ, Chen TC, Hinton DR, et al. Surgery of the third ventricle, 2nd ed. Baltimore: Williams \& Wilkins, 1998:1096-125.

4 Barton CW. Evaluation and treatment of headache patients in the emergency department: a survey. Headache 1995:35:91-4.

5 Stoodley MA, Nguyen TP, Robbins P. Familial fatal and near-fatal third ventricle colloid cysts. Aust NZ J Surg 1999;69:733-6.

6 Mathiesen T, Grane P, Lindrgren, et al. Third ventricle colloid cysts: a consecutive 12-year series. J Neurosurg 1997:86:5-12.

7 Batnitzky S, Sarwar M, Leeds NE, et al. Colloid cysts of the third ventricle. Radiology 1974;112:327-41.

8 Mamourian AC, Cromwell LD, Harbaugh RE. Colloid cyst of the third ventricle: Sometimes more conspicuous on CT than MR. AJNR Am J Neuroradiol 1998;19:875-8.

9 Hall WA, Lunsford LD. Changing concepts in the treatment of colloid cysts. An 11-year experience in the CT era. J Neurosurg 1987:66:86-91.

10 Partington MW, Bookalil AJ. Familial colloid cysts of the third ventricle. Clin Genet 2004;66:473-5.

11 Nader-Sepahi A, Hamlyn PJ. Familial colloid cysts of the third ventricle: case report. Neurosurgery 2000;46:751-3.

12 Akins PT, Roberts R, Coxe WS, et al. Familial colloid cyst of the third ventricle: case report and review of associated conditions. Neurosurgery 1996;38:392-5.

13 Ibrahim AW, Farag H, Naguib M, et al. Neuroepithelial (colloid) cyst of the third ventricle in identical twins. J Neurosurg 1986;65:401-3.

\section{Spontaneous coronary artery dissection}

\section{P Naughton, L Nolke, D Veerasingam, J McCarthy}

Spontaneous coronary artery dissection is a rare cause of myocardial ischaemia or sudden death, predominantly affecting young women with no known risk factors for cardiovascular disease. The case described emphasises the benefit of early diagnosis and the need to individualise management based on patient response to treatment. pontaneous coronary artery dissection is a rare cause of myocardial ischaemia or sudden death. Despite first being described as long ago as 1931, by Pretty, ${ }^{1}$ the diagnosis is often delayed or missed. This condition predominantly affects young women with no known risk

Abbreviation: $L A D$, left anterior descending 
factors for cardiovascular disease. We describe a case that emphasises the benefit of early diagnosis and the need to individualise management based on patient response to treatment.

\section{CASE REPORT}

A 43 year old woman presented to the accident and emergency department of a regional university hospital following two episodes of retrosternal chest pain each lasting 10 minutes. She had no known risk factors for ischaemic heart disease. Her last pregnancy was 2 years previously. ECG on admission was normal but subsequently demonstrated $\mathrm{T}$ wave inversion in the anterior leads. Troponin levels were elevated. Coronary angiography was performed and revealed a $75 \%$ narrowing of the mid left anterior descending (LAD) artery due to a dissection (fig 1). Left ventricular ejection systolic fraction was $50 \%$.

The patient was initially managed medically but continued to experience chest pain. Repeat coronary angiography revealed further extension of the dissection with total occlusion of the mid LAD artery and moderate apical dyskinesia. She was referred for surgical management and underwent emergency double coronary artery bypass with a left internal mammary artery graft to the LAD and a reversed saphenous vein graft to her first diagonal. Her post-operative recovery was unremarkable and she was discharged home 10 days later. She was asymptomatic at the time of her 6 month review.

\section{DISCUSSION}

Spontaneous coronary artery dissection has been defined as the presence of a haematoma within the media of the coronary artery that impinges upon the lumen of the artery. ${ }^{2}$ Secondary causes of coronary artery dissection must be excluded before a coronary artery dissection is deemed spontaneous. These secondary causes include cardiac catheterisation, ${ }^{3}$ chest trauma, ${ }^{4}$ extension of an aortic dissection, ${ }^{5}$ and cardiac surgery. The majority $(80 \%)$ of cases of spontaneous coronary artery dissection occur in women, with one third occurring in the third trimester of pregnancy or within the first 3 months postpartum. ${ }^{6}$ The LAD is affected in $80 \%$ of cases, ${ }^{7}$ which may explain the high mortality rates. There is a clinical spectrum from stable to unstable angina, myocardial infarction, cardiogenic shock, and sudden death.

The aetiology of spontaneous coronary artery dissection is poorly understood, but probably is a combination of factors. Unlike aortic dissections, no association with hypertension has been noted. ${ }^{8}$ The possible causes may be divided into three categories. Firstly, physiological changes during pregnancy are responsible for degeneration of collagen, ${ }^{9}$ and subsequent haemodynamic stresses during delivery may then facilitate dissection. Vascular events are relatively common during pregnancy; $10-20 \%$ of all maternal deaths are

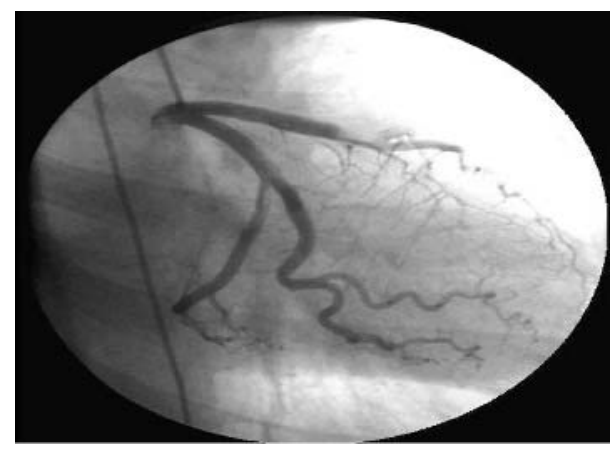

Figure 1 Coronary arterial angiogram: dissection at the mid LAD. secondary to vascular events. ${ }^{10}$ Secondly, rupture of the vas vasorum into the media has been implicated as an initiating site for coronary artery dissection. ${ }^{11}$ Finally, histological analysis of the involved area of coronary artery demonstrates periadventitial infiltration. ${ }^{2}$ These infiltrates consist of eosinophils, histiocytes, and lymphocytes. Robinowitz ${ }^{2}$ reported that these lymphocytes and eosinophils secrete lytic enzymes and major basic protein, leading to medial weakening and dissection.

The initial management of coronary artery dissection is similar to that of coronary artery disease without dissection. Early catheterisation is essential to determine diagnosis and guide subsequent management. There are several angiographical findings characteristic of spontaneous coronary artery dissection, including a radiolucent line that can be seen separating the true and false lumen of the vessel. This line represents the intima and inner portion of the media, which have been dislodged and now separate the true and false channels. The false lumen may appear as a saccular area next to the vessel. There may be compression of the true lumen by the false lumen, resulting in changes in the calibre of vessels. ${ }^{12}$

Prognosis is good for those who survive the initial event; ${ }^{7}$ 12 year asymptomatic survival has been described with conservative management. ${ }^{13}$ The decision to thrombolyse may enable flow to be re-established in the true lumen; however, there is also the risk that thrombolysis may aggravate bleeding and the dissection. ${ }^{7}$ Patients who survive the initial event but remain unstable or suffer ongoing inducible ischaemia, as reported in this case, should be managed by interventional cardiology or surgery. Both angioplasty and stenting have also been described, with excellent results in single vessel disease, however, this must be balanced with the potential of entering the false lumen during passage of the guidewire and the risk of coronary occlusion or perforation. ${ }^{6}$ Previously, it has been recommended to perform coronary artery bypass surgery for all patients with spontaneous dissection, ${ }^{14}$ however, this must be considered in light of results achieved by stenting, difficulty noted in grafting the dissected artery, and perioperative morbidity and mortality.

\section{CONCLUSION}

Spontaneous coronary artery dissection is a rare condition that should be suspected and excluded in young women who present with acute coronary events. Management is reliant on immediate coronary angiography and should be individualised to angiographic findings and the patient's response to initial aggressive medical management.

\section{Authors' affiliations}

P Naughton, L Nolke, D Veerasingam, J McCarthy, Department of Cardiothoracic Surgery, Mater Misercordiae Hospital, Eccles St, Dublin 9, Republic of Ireland

Competing interests: none declared

Correspondence to: Dr P Naughton, Department of Cardiothoracic Surgery, Mater Misercordiae Hospital, Eccles St, Dublin 9, Republic of Ireland; peternaughton74@eircom.net

Accepted for publication 31 December 2004

\section{REFERENCES}

1 Pretty HC. Dissecting aneurysm of coronary artery in a woman aged 42 : rupture. Br Med J 1931;1:667.

2 Robinowitz M, Virmani R, McAllister HA. Spontaneous coronary artery dissection and eosinophilic inflammation: a cause and effect relationship? Am J Med 1982;72:923-27.

3 Guss SB, Zir LM, Garrison HB, et al. Coronary occlusion during coronary angiography. Circulation 1975;52:1063-8.

4 Grady AE, Cowley MJ, Vetrovec GW. Traumatic dissecting coronary arteril aneurysm with subsequent healing. Am J Med 1986;80:317-19. 
5 Claudon DG, Claudon DB, Edwards JE. Primary dissecting aneurysm of coronary artery. Circulation 1972;45:259-6.

6 Kay P, Wilkins GT, Williams MJA. Spontaneous coronary artery dissection presenting as unstable angina. J Inv Card 1998;10:274-6.

7 Elming H, Kober L. Spontaneous coronary artery dissection. Scand Cardiovasc 1999;33:175-79.

8 Kearney $\mathbf{P}$, Singh $\mathrm{H}$, Hutter J, et al. Spontaneous coronary artery dissection: a report of three cases and review of the literature. Postgrad Med J 1993:69:940-5

9 Manalo-Esterella P, Baker E. Histological findings in the human aortic media associated with pregnancy. Arch Path 1967;83:336-41.
10 Byrans FE. Vascular accidents in maternal mortality. Clin Obstet Gynecol 1963;6:861-73.

11 Bager AC, Beeuwkes R, Lainey L, et al. Hypothesis: vasa vasorum and neovascularisation of human coronary arteries. A possible role in the pathophysiology of atherosclerosis. N Engl J Med 1984;310:175-7.

12 Jorgenson MB, Aharonian V, Mansukhani $P$, et al. Spontaneous coronary dissection: a cluster of cases with rare finding. Am Heart J 1994; 127:1382-7.

13 Demaio S, Kinsella S, Silverman M. Clinical course and long-term prognosis of spontaneous coronary artery dissection. Am J Cardiol 1989:64:471-4.

14 Thayer JO, Healy RW, Maggs PR. Spontaneous coronary artery dissection. Ann Thorac Surg 1087;44:97-102.

\section{Look before you pack: key point in epistaxis management}

\section{K Aneeshkumar, E Osman, R Shahab, N J Roland}

Emerg Med J 2005;22:912-913. doi: 10.1136/emj.2004.022434

We report a patient with epistaxis who used cotton wool to pack his nose before reaching the hospital, and underwent further packing in the accident and emergency department, which probably pushed the cottonwool further back. This led to the formation of foreign body granuloma inside the nasal cavity. It is difficult to examine the nose without proper equipment and experience, and the examination is more difficult in the presence of active bleeding to find a foreign body such as cotton wool. Hence, it is important to ask the patient about any temporary pack they have used in the nose and to look for and remove it before inserting a proper pack. It is also important for trainees to have a better understanding of the different levels of management of epistaxis. Hence, we propose the term "epistaxis management ladder" for easy understanding of the treatment of epistaxis.

E pistaxis is a common otolaryngology emergency, and is often managed by junior doctors. With the introduction of European working time directives and cross cover on calls, it has been argued that this common and potentially life threatening emergency may be managed by doctors with little training in its management. Nasal packing has been made simple by the introduction of packs such as Merocel and Rapid Rhino, and these can be used effectively to control bleeding by medical personnel without much otolaryngology experience. This case stresses the importance of examination of the nasal cavity before the insertion of the pack to find the site of bleeding and any foreign bodies inserted by the patient to control bleeding.

\section{CASE REPORT}

A 62 year old man presented to the accident and emergency (A\&E) department with epistaxis. He was packed in the A\&E department with Merocel and later with Vaseline gauze, which helped to stop the bleeding. The patient was admitted for observation. The nasal packs were removed after 48 hours and he was sent home with an outpatient appointment to examine the nose. On review, he did not have any further bleeds, but on fibreoptic endoscopy, some crusts were noted in the right nostril, which were difficult to remove. The patient was given saline douches and reviewed again. On this visit, two cottonwool balls were seen in the right nostril. One was removed in the clinic and the other had to be removed under general anaesthetic. Examination under general anaesthesia showed granulation tissue formation near the foreign body, which was confirmed as foreign body granuloma on histology.

\section{DISCUSSION}

Nasal packing is a common method to control epistaxis. With the introduction of cross cover on call between specialties to achieve the European time directive targets, nasal packing is more frequently performed by trainee staff with less ENT experience. Patients presenting with epistaxis should have a thorough examination using a Thudicum speculum and an endoscope to identify the bleeding point, and if possible, the bleeding vessel should be cauterized. If the bleeding cannot be stopped or recurs, then the nose should be packed. ${ }^{1}$ This is not possible without proper training. To ensure good quality service in the management of epistaxis in the National Health Service, all the doctors in the accident and emergency department and all surgical Senior House Officers who cover the ear, nose, and throat department during their on call duty should be adequately trained in management of this common condition.

It is a natural tendency to control bleeding by applying pressure. Our patient tried it with cotton wool. When an inexperienced trainee is packing the nose in such patients, it is possible to push these foreign bodies further into the nose. Along with other routine history taking for epistaxis, it is important to ask the patient about any temporary pack used before attending the hospital.

After removing the packs, it may be difficult to get a good view inside the nose because of blood clots, which the doctor may be reluctant to move as doing so may precipitate bleeding that may require repacking. In these situations, it is important to review these patients later in the outpatient department to examine the nose thoroughly.

To our knowledge, only three cases of pyogenic granulomas have been reported as a complication of nasal packing. ${ }^{2-4}$ Only two cases of foreign body granulomas of the nose have been reported in the literature. ${ }^{56}$

To avoid these potential complications and for an easy understanding of the management of epistaxis, we propose the term "epistaxis management ladder"(table 1).

\section{Epistaxis Management Ladder}

Intiially, the doctor should check pulse and blood pressure, and using a large bore intravenous cannula, take a blood sample, to be sent for full blood count, clotting screen (international normalised ratio if patient is on warfarin) and

Abbreviation: A\&E, accident and emergency 


\section{Table 1 Steps of the epistaxis management ladder}

Step 1

The patient should sit with the upper part of the body tilted forward and the mouth open so that they can spit out the blood instead of swallowing.

Pinch all the cartilaginous part of the nose together between the thumb and index finger. Hold the nose for at least 5 minutes (timed by the clock)

Use Thudicum nasal speculum to examine the nose

Remove the blood clot using suction

Use cophenylcaine nasal spray

Examine thoroughly to identify the bleeding point

Use silver nitrate to cauterise the bleeding point

If bleeding point cannot be seen: nasal endoscopy and cautery using suction diathermy

If not competent to use nasal endoscope or bleeding point cannot be identified using endoscope, go to step 2

Step 2

Anterior nasal packing using Merocel, Rapidrhino, Vaseline gauze, or

bismuth iodine paraffin paste

If not controlled, go to step 3

Step 3

Post nasal packing using Foley's catheter, or Brighton, Simpson, or

Bivona balloon

If not controlled, go to step 4

Step 4

Under general anaesthesia the following may need to be performed:

Examination of nose and cautery of bleeding vessel or

Tight nasal and post-nasal packing

Ligation of sphenopalatine artery or anterior ethmoidal artery or

external carotid artery or internal maxillary artery

Angiography and embolisation

Submucous resection of septum

blood group. Resuscitation becomes the paramount consideration in the elderly patient with epistaxis. ${ }^{1}$

\section{First step}

A thorough examination of the nose should be carried out. Examination will be made difficult in presence of active bleeding. Pinching the nose at the cartilaginous area often stops bleeding, facilitating examination. Every attempt should then be made to identify the bleeding point. Cocaine is widely used as a local anaesthetic in the nose; however, it is potentially toxic, a known drug of addiction, and its spray delivery devices can theoretically transfer infection. Cophenylcaine (5\% lidocaine and $0.5 \%$ phenylephrine) is an excellent alternative to cocaine nasal spray. The common site of bleeding is the Little's area, ${ }^{7}$ which is easily visualised with a Thudicum speculum and head light.

For doctors working in A\&E with limited equipment, step 1 will often be all that is required to stop the bleeding.

\section{Second step}

If a bleeding point cannot be identified, second step in the management is by anterior nasal packing. This can be done with packing materials such as Merocel, Rapid Rhino, Vaseline gauze, or bismuth iodine paraffin paste.

\section{Third step}

The third step of the ladder is postnasal packing, performed if the patient continues to bleed after the first two steps. Postnasal packing can be performed using Foley's catheter, or Brighton, Simpson, or Bivona balloon.

\section{Fourth step}

If the bleeding is not controlled with the first three steps, the patient will need general anaesthetic and the following procedures may need to be performed: ${ }^{1}(a)$ examination of the nose and cautery of bleeding vessel; $(b)$ tight nasal and postnasal packing; (c) ligation of the sphenopalatine artery and/or anterior ethmoidal artery ligation or external carotid artery or internal maxillary artery; $(d)$ angiography and embolisation; and (e) submucous resection of the septum.

\section{CONCLUSION}

Before packing the nose, it is important to ask the patient about any temporary pack they have used in the nose before presentation, and to look for and remove it before inserting a proper pack. The importance of examination of the nose before inserting the pack cannot be overstressed. We propose the term "epistaxis management ladder" for a better understanding of the different levels of control of nosebleed.

\section{Authors' affiliations}

M K Aneeshkumar, E Osman, R Shahab, N J Roland, Department of Otorhinolaryngology and Head and Neck Surgery, University Hospital Aintree, Lower Lane, Liverpool, UK

Competing interests: none declared

Correspondence to: Mr M K Aneeshkumar, 19 Farm Meadow Road, Orrell, Wigan WN5 8TE, UK; mkaneesh@hotmail.com

Accepted for publication 7 January 2005

\section{REFERENCES}

1 Watkinson JC. Epistxis. In:Kerr AG. Scott-Brown's otolaryngology-rhinology, 6th ed. Oxford: Butterworth, 1997.

2 Lee HM, Lee SH, Hwang SJ. A giant pyogenic granuloma in the nasal cavity caused by nasal packing. Eur Arch Otorhinolaryngol 2002;259:231-3.

3 Sheen TS, Ko JY, Hsu YH. Pyogenic granuloma-an uncommon complication of nasal packing. Am J Rhinol 1997:11:225-7.

4 Bhattacharyya N, Wenokur RK, Goodman ML. Endoscopic excision of a giant pyogenic granuloma of the nasal cavity caused by nasal packing. Rhinology 1997;35:44-5.

5 Tsur H, Lin E. Glass foreign body granuloma of the nose. Injury 1982;13:343-5.

6 Asano K. Foreign body granuloma caused by a broken silver needle for acupuncture Jibiinkoka 1969:41:289-91.

7 Razdan U, Zada R, Chaturvedi VN. Epistaxis: study of aetiology, site and side of bleeding. Indian J Med Sci 1999;53:545-52.

\section{Cardiac luxation: an unusual complication of a log roll}

\section{Kerins, E Maguire, C Lacy}

Cardiac luxation is a rare but potentially fatal consequence of blunt thoracic trauma. We present a case of a pericardial tear with cardiac luxation following blunt chest trauma. It is hypothesised that the cardiac luxation occurred while log rolling the patient during the initial assessment. This report stresses the need to be aware of the potential for such a complication.

Abbreviations: CXR, chest $x$ ray; ICU, intensive care unit 
A 21 year old man was brought by ambulance to the emergency department. He had been travelling by motorcycle at approximately 30 miles per hour when he was hit on the left side by a car.

On initial examination, the patient's airway was intact, his cervical spine adequately immobilised, and his trachea central. He was breathing spontaneously, with good bilateral air entry. His oxygen saturation was $94 \%$ on $15 \mathrm{l} / \mathrm{min}$ of oxygen, pulse rate 120 beats/min, heart sounds normal, and blood pressure $110 / 60$ with warm peripheries and no evidence of external haemorrhage. He responded well to 2 litres of intravenous crystalloid. His chest $x$ ray (CXR) showed a right basal pulmonary contusion and a prominent right heart border. Other injuries found on examination were mild left upper quadrant abdominal tenderness, a poorly palpable left brachial pulse, reduced sensation and muscular paralysis in the left arm, and a slowly expanding haematoma at the base of the left anterior triangle of his neck.

During assessment, the patient was log rolled to the right, after which he became intermittently hypotensive, requiring further bolus fluid administration and 2 units of packed red cells. Reassessment of his chest revealed reduced air entry bilaterally with oxygen saturation of $90 \%$ on pulse oximetry. Bilateral needle thoracocenteses were performed followed by chest drain insertion, resulting in improvement in air entry and oxygen saturation, and yielding 100 millilitres of blood immediately from the left side.

A repeat CXR showed marked displacement of the cardiac silhouette to the right (fig 1). ECG showed ST segment elevation in the anterolateral and inferior leads. Transthoracic echocardiography demonstrated no abnormality, although the views obtained were suboptimum. This was suspected to be due to a possible anterior mediastinal haematoma.

The fluctuating blood pressure, cardiac silhouette displacement, poor cardiac views on echocardiography, neurovascular compromise of the left arm, and expanding haematoma at the base of his neck led us to consider the possibility of great vessel injury. The patient therefore underwent contrast enhanced CT scanning of his chest, neck, and abdomen. The scans revealed an anterior mediastinal haematoma, fractured left scapula, extensive bilateral lower lobe contusions, fracture of the transverse process of the sixth cervical vertebra, and a ruptured spleen with contained haematoma, but no abnormality of the great or subclavian vessels. The patient underwent laparotomy and splenectomy, and was subsequently transferred to the intensive care unit (ICU).

In ICU, his apex beat became increasingly visible on the right side of his chest with obvious mediastinal displacement on CXR. Initial cardiothoracic opinion suggested that this

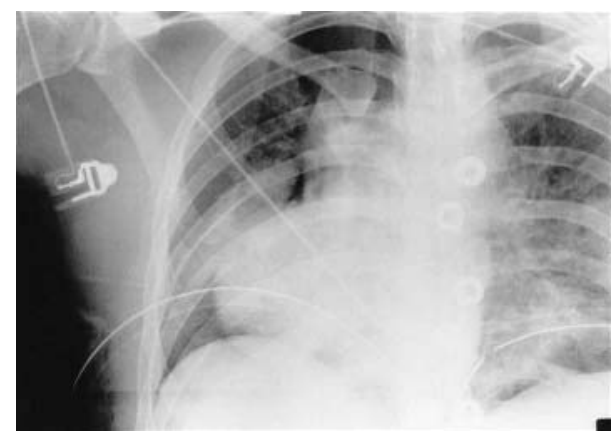

Figure 1 CT scan showing anterior mediastinal haematoma, fractured left scapula, extensive bilateral lower lobe contusions, fracture of the transverse process of the sixth cervical vertebra, and a ruptured spleen with contained haematoma. was caused by hyperinflation of the left lung with associated collapse of the right, and positional changes were advised. However, the mediastinal shift persisted despite repositioning the patient. A repeat echocardiogram (transoesophageal) on day 3 showed his heart had rotated $90^{\circ}$ to the right. He returned to the operating theatre for an exploratory thoracotomy and was found to have a large pericardial tear extending from the superior vena cava to the inferior vena cava with cardiac luxation to the right. His heart was repositioned into the sac and the defect repaired with bovine pericardium. He made a good postoperative recovery and at review, 3 months postinjury, he was well, with normal cardiac position on a transthoracic ultrasound examination. His brachial plexus injury was improving with conservative management.

\section{DISCUSSION}

Pericardial rupture represents a rare but potentially fatal consequence of serious thoracic trauma. ${ }^{12}$ Cases of traumatic rupture may involve the diaphragmatic pericardium, pleuropericardium or both and can be right (36\%) or left sided $(64 \%){ }^{2}$ A pericardial tear $8-12 \mathrm{~cm}$ long is the most dangerous type of tear, as it exposes the heart to luxation and the luxated heart may then become incarcerated by the edges of the pericardial tear, leading to sudden deterioration. ${ }^{3}$

The diagnosis of acute pericardial rupture is generally very difficult, ${ }^{1}$ and is rarely made preoperatively. ${ }^{4}$ It is suggested intraoperatively by ongoing cardiovascular instability after repair of abdominal or other injuries. Some diagnostic clues have been described, such as absent heart sounds, an abnormal ECG pattern, pericardial tamponade, ${ }^{3}$ or a characteristic murmur described by Morel-Lavallee in $1864,{ }^{5}$ bruit de Moulin, which is thought to occur as a result of a haemopneumopericardium.

There has also been a report of a case presenting almost 3 weeks after the precipitating injury. ${ }^{6}$ This patient had a pelvic fracture requiring him to lie supine for 2 weeks. When he was first allowed to sit up, he developed sudden chest pain, which was subsequently proven to be due to herniation of the heart through the pleuropericardium.

Radiologically, rupture can be suggested by a pneumopericardium or pericardial effusion. The heart may be displaced or simply enlarged. ${ }^{7}$ Angiography may be used to study an abnormal mediastinum and is more often diagnostic when pericardial rupture is associated with cardiac luxation than without. ${ }^{289}$ In the presence of diaphragmatic pericardial tears, computed tomography may further aid in diagnosis by identification of any abnormal gas distribution or organ positioning caused by herniation of viscera that contains air into the pericardium.

Our case involved a patient with a right sided pleuropericardial tear. We believe that our patient sustained a pericardial tear as a consequence of blunt thoracic trauma and that he subsequently developed cardiac luxation during a log roll to the right side. This is supported by the change in cardiac silhouette on CXR and his fluctuating haemodynamic profile following the log roll. Intermittent luxation with associated hypotension has been described previously, ${ }^{10}$ but not as a consequence of a log roll.

Our case highlights the need to have a high index of suspicion of pericardial rupture with cardiac luxation in patients with blunt chest trauma whose haemodynamic status deteriorates following a log roll.

\section{Authors' affiliations}

M Kerins, E Maguire, C Lacy, Department of Emergency Medicine, St. Thomas's Hospital, London, UK

Competing interests: none declared 
Correspondence to: Dr C Lacy, Department of Emergency Medicine, St. Thomas's Hospital, London, UK; chris.lacy@gstt.sthames.nhs.uk

Accepted for publication 30 June 2004

\section{REFERENCES}

1 Fulda G, Rudriquez A, Turney SZ, et al. Blunt Traumatic pericardial rupture: A 10 year experience. $J$ Cardiovasc Surg 1990;31:525-30.

2 Clark DE, Wiles CS, Lim MK, et al. Traumatic rupture of the pericardium. Surgery 1983;93:495-503.

3 Aho AJ, Vanttinen EA, Nelimarkka Ol. Rupture of the pericardium with luxation of the heart after blunt trauma. J Trauma 1987;27:560-3.
4 Geiran O, Birkeland S. Pre-operative clinical diagnosis in pericardial rupture. Scan J Thorac Cardiovasc Surg 1974;8:188-91.

5 Morel-Lavallee. Rupture de pericarde; bruit de roue hydralique; bruit de Moulin. Gaz Med Paris 1864;19:695-6, 729-30, 771-2, 803-8.

6 Pascal T, Saux P, Lonjon T, et al. Diagnosis by video-assisted thoracoscopy of traumatic pericardial rupture with delayed luxation of the heart: case report. $J$ Trauma June, 1995;38:967-70.

7 Mirvis SE, Young JWR. Imaging in trauma and critical care. Lippincott: Williams \& Wilkins, 1996:142.

8 Clifford RP, Gill KS. Traumatic rupture of the pericardium with dislocation of the heart. Injury 1984; 16:123-5.

9 Cavanaugh DG, Paris J. Pericardial rupture with complete luxation of the heart. Milit Med 1983; 148:28-9.

10 Bogers, et al. Cardiac subluxation in traumatic rupture of diaphragm and pericardium. Thorac Cardiovasc Surgeon 1986;34:132-4.

\section{Rupture of the tibialis posterior tendon: an important differential in the assessment of ankle injuries}

\section{A P Foster, N W Thompson, M D Crone, A P Charlwood}

Rupture of the tibialis posterior tendon can be missed. We report a case of posterior tibialis tendon rupture that, owing to misdiagnosis, resulted in a significant foot deformity requiring arthrodesis for chronic pain.

\footnotetext{
A
} 71 year old woman was referred to the orthopaedic outpatient clinic with chronic right ankle pain. She was also concerned regarding the appearance of the foot and was having difficulty with normal footwear. Of note, 18 months previously, she had sustained an injury to the right ankle and recalled an audible crack at the time of the event. At the time, 24 following the injury, she had attended the accident and emergency department, and a diagnosis of ankle sprain had been made based on normal appearance on radiographs. There was no relevant past medical history on systematic questioning.

Clinical examination revealed a flat, everted foot with an obvious valgus heel position. Weakness of inversion and an inability to raise the affected heel off the ground was evident. From behind, the forefoot appeared grossly abducted, and pain was elicited on both ankle and subtalar joint movements.

Magnetic resonance imaging of the right ankle revealed the presence of a midsubstance tear affecting the tibialis posterior tendon with surrounding oedema (fig 1). A triple arthrodesis was performed with good results.

\section{DISCUSSION}

The tibialis posterior functions primarily as a plantar flexor and invertor of the foot. ${ }^{1}$ During gait, the mechanical demand on the tendon is high, particularly just after heel strike as the hindfoot moves from a position of loaded eversion into increasing inversion. ${ }^{2}$ It is vulnerable to injury owing to a localised hypovascularity in a critical zone just posterior to the medial malleolus, which is the most common site of tendon rupture. ${ }^{3}$

Despite being a well documented clinical entity, rupture of the tibialis posterior tendon can be misdiagnosed. Mann and Thompson $^{4}$ reported a series of 17 patients with posterior tibial tendon rupture. They revealed an average time to treatment of 43 months and in all but two of the patients, incorrect diagnosis had been made on initial assessment.

In almost all patients who sustain a rupture of the tibialis posterior tendon, there is a history of ankle trauma. ${ }^{4-6}$ Typically the mechanism of injury is forced eversion. Younger patients, usually athletes, tend to sustain a traumatic avulsion of the tendon at its insertion into the navicular, while middle aged or elderly individuals often suffer a mid-substance inflammatory or degenerative type tear, ${ }^{2}$ as in our case.

Initial symptoms are usually related to the tendon pathology, including pain along the course of the tendon, weakness, and loss of the medial longitudinal arch, resulting in the appearance of a flatfoot deformity. ${ }^{7}$ On examination, weakness of inversion is evident. Toe raises are difficult, and there is often delay in or lack of heel varus with toe raising on the affected side when viewed from behind. ${ }^{7}$ The "too many toes" sign, ${ }^{8}$ which is the appearance of more of the lesser digits on the affected side when viewed from behind, may be apparent and is the result of forefoot abduction. A defect may be palpable along the course of the tendon. With time, a progressive planovalgus foot develops, and symptoms may be related to the fixed position of the foot and the development of degenerative joint disease. ${ }^{7}$

Plain radiographs are of limited value, as rupture of the tibialis posterior tendon is essentially a clinical diagnosis, although they may be of value to exclude underlying bony pathology. The tibialis posterior tendon is best imaged either by ultrasound 9 or magnetic resonance imaging. ${ }^{10}{ }^{11}$

Non-operative treatment is limited to those patients with a partial or longitudinal tear, or where surgery is contraindicated because of significant systemic disease or advanced age. Options include shoe modifications, orthotic support, and bracing. ${ }^{12}$ Surgical treatment may involve soft tissue procedures such as primary repair or tendon transfer, flat foot reconstruction, or arthrodesis, or a combination of techniques depending on the stage of presentation, the presence of collapse of the medial longitudinal arch, or the development of degenerative joint disease. ${ }^{7}$

In conclusion, rupture of the tibialis posterior tendon should be considered in the differential diagnosis when assessing ankle trauma particularly in the presence of normal radiographs. In those patients where there is a high index of 


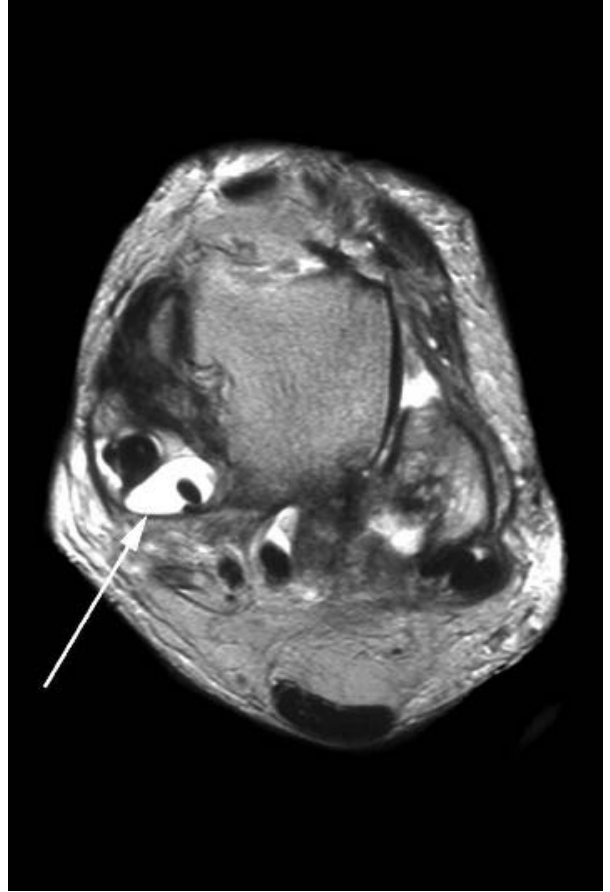

Figure 1 Magnetic resonance image demonstrating a midsubstance tear affecting the tibialis posterior tendon with surrounding oedema (white arrow).

suspicion of tibialis posterior tendon rupture, re-evaluation at an early stage when pain and swelling have subsided may help to confirm the diagnosis. Early specialist referral is also essential.

\begin{abstract}
Authors' affiliations
A P Foster, N W Thompson, A P Charlwood, Department of

Orthopaedics and Trauma, Altnagelvin Area Hospital, Londonderry, UK M D Crone, Department of Radiology, Musgrave Park Hospital, Belfast, UK

Competing interests: none declared
\end{abstract}

Correspondence to: Mr A P Foster, 1 Rochester Drive, Belfast BT6 9JX, UK; apfoster@doctors.org.uk

Accepted for publication 22 August 2004

\section{REFERENCES}

Basmajian JV, Stecko G. The role of muscles in arch support of the foot. J Bone Joint Surg 1963;45A: 1 184-90.

2 Conti SF. Posterior tibial tendon problems in athletes. Orthop Clin North Am 1994;25:109-21.

3 Frey C, Shereff $M$, Greenidge N. Vascularity of the posterior tibial tendon. $J$ Bone Joint Surg 1990;72A:884-8.

4 Mann FA, Thompson FM. Rupture of the posterior tibial tendon causing flatfoot. J Bone Joint Surg 1985;67A:556-61.

5 Frey C, Shereff M. Tendon injuries about the ankle in athletes. Clin Sports Med 1988;7:103-18.

6 Johnson KA. Tibial posterior tendon rupture. Clin Orthop 1983:177:140-7.

7 Mendicino SS. Posterior tibial tendon dysfunction. Diagnosis, evaluation and treatment. Clin Podiatr Med Surg 2000;17:33-54.

8 Johnson KA, Strom DE. Tibialis posterior tendon dysfuncion. Clin Orthop 1989:239:196-206.

9 Rockett M, Waitches G, Sudakoff $G$, et al. Use of ultrasonography versus magnetic resonance imaging for tendon abnormalities around the ankle. Foot Ankle Int 1998;19:604-11.

10 Hogan J. Posterior tibial tendon dysfunction and MRI. J Foot Ankle Surg 1993;32:467-72.

11 Lim P, Schweitzer M, Deely D, et al. Posterior tibial tendon dysfunction: Secondary MR signs. Foot Ankle Int 1997; 18:658-63.

12 Chao W, Wapner K, Lee T, et al. Non-operative management of posterior tibial tendon dysfunction. Foot Ankle Int $1996 ; 17: 736-41$

\title{
Stab to second intercostal space: a bubbling extrapleural wound
}

\author{
A Jabbar, J V Reynolds, P K Plunkett
}

\begin{abstract}
A 37 year old man was found collapsed at the roadside and taken to the emergency department. Communication was difficult, as the patient could not speak English. There was a wound in the left second intercostal space on the midclavicular line, which was bleeding and was bubbling air. A drain was inserted, bleeding controlled, and his wounds sutured. Chest $x$ ray later confirmed satisfactory placement of the drain. The following day, swelling and discharge indicated oesophageal damage, which was later confirmed by gastrografin swallow. With conservative management in hospital for 2 weeks, he made a full recovery and was discharged.
\end{abstract}

A 37 year old man was found collapsed at the roadside and taken to the emergency department by ambulance at 0200 . He had sustained a stab wound to the left anterior chest and an injury to the left side of the head. Further history was unobtainable, as the patient could not speak or understand English.
The patient was alert, with no airway compromise and adequate breathing. There was no evidence of neck injury but, in view of his head injury and communication difficulty, his neck was immobilised. Pulse was 110 beats/min, blood pressure 130/70 $\mathrm{mm} \mathrm{Hg}$, respiratory rate 24 breaths/min, oxygen saturation $96 \%$ on room air and capillary glucose $7 \mathrm{mmol} / \mathrm{l}$.

The patient had a $30 \mathrm{~mm}$ laceration behind the left ear. More importantly, there was a laceration measuring $20 \mathrm{~mm} \times 10 \mathrm{~mm}$ in the left second intercostal space on the midclavicular line, which was bleeding and was bubbling air. Bleeding was controlled with digital pressure, and a drain was rapidly inserted into the fiftth intercostal space, without a preliminary chest $x$ ray (CXR). His lacerations were sutured. CXR later confirmed satisfactory placement of the drain, with inflated lungs, and the patient was admitted to the emergency observation ward.

Next morning, a translator was employed to assist with communication. The patient was stable and feeling well. The

Abbreviation: CXR, chest $x$ ray 


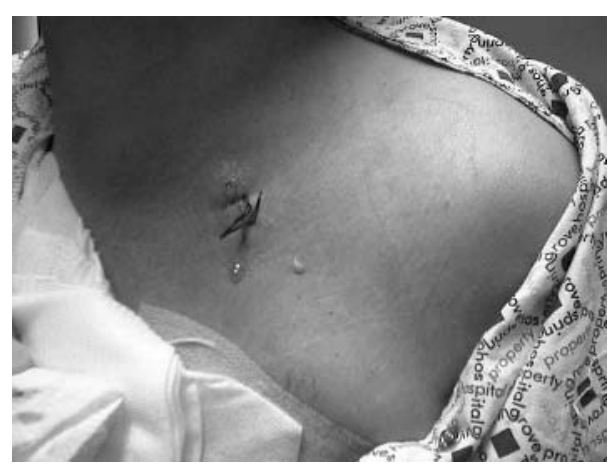

Figure 1 Discharge from wound on left upper chest.

discomfort. He had developed a small swelling in the left upper chest and lower neck region. There was a porridge-like discharge from the chest wound, which appeared like anchovy sauce, with a layer of stringy clear fluid, suggestive of saliva. There was also some air leakage (fig 1). CXR revealed surgical emphysema in the left chest wall and the neck. A provisional diagnosis of oesophageal injury was made. An urgent gastrografin swallow showed leakage from the lower cervical oesophagus tracking laterally through the soft tissues anterior to the left lung apex (fig 2).

The consultant in emergency medicine reviewed the patient, along with an oesophageal surgeon, who opted for conservative management. The patient was placed on total parenteral nutrition. A computed tomography scan next day confirmed leakage from the oesophagus, just above the level of the thoracic inlet, with a haematoma in the mediastinum and small bilateral pleural effusion. Subsequent angiogram was normal.

The patient's chest wound discharged for 2 weeks, but his stay in hospital remained uneventful. He was discharged home on day 18, following a gastrografin swallow that confirmed no further leakage.

\section{DISCUSSION}

Penetrating injuries to the chest and neck following assault with knives or bullets are relatively common. The second intercostal space has been considered safe for chest decompression and occasional insertion of chest drainage. However, its proximity to zone I of the neck and the vital structures in the thoracic outlet make it a special case. In our patient, the injury was due to a long knife, which traversed the chest
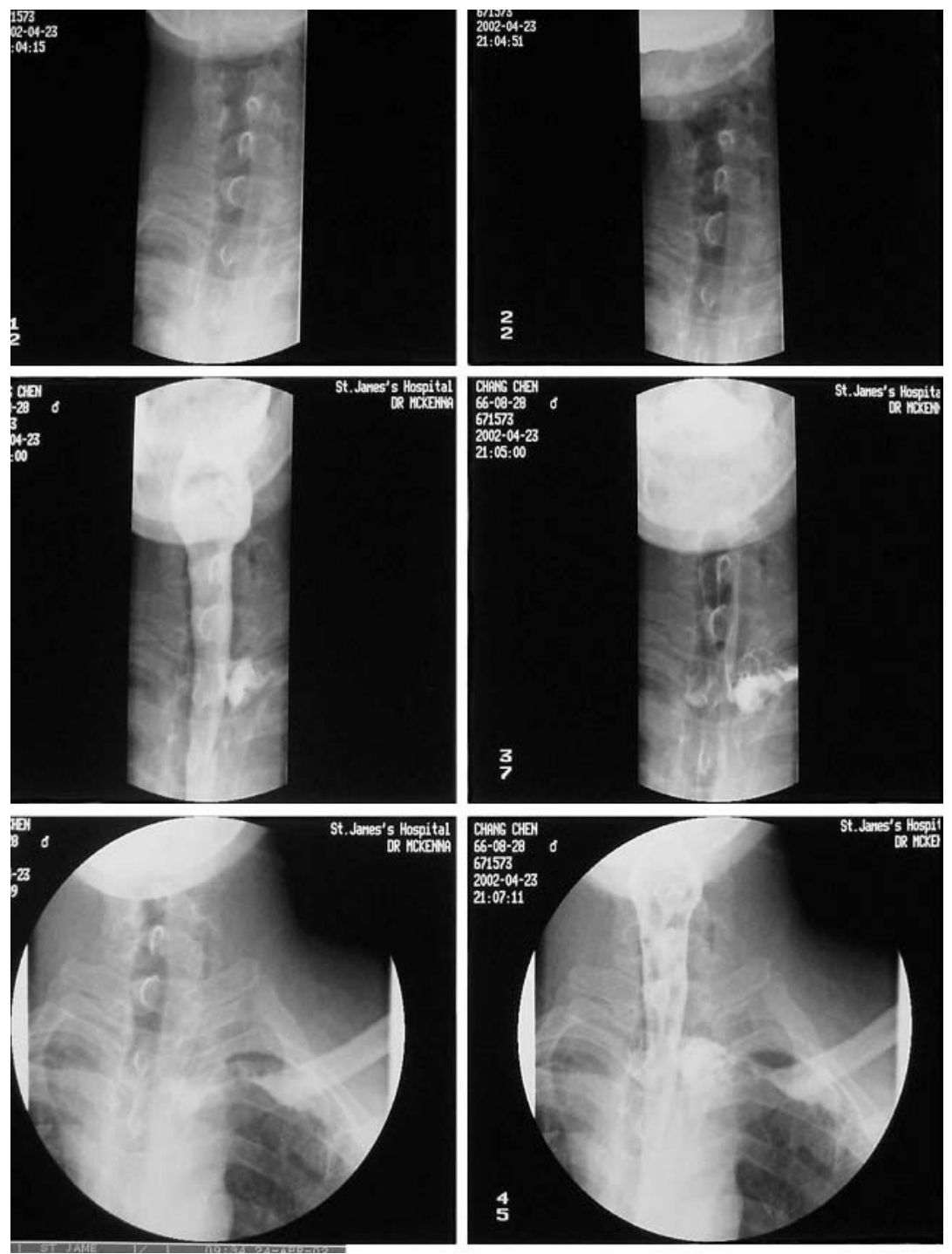

Figure 2 Radiography showed leakage from the lower cervical oesophagus tracking laterally through the soft tissues anterior to the left lung apex. 
superficial to the rib cage and above the clavicle, causing a zone I injury to the neck.

During the 1960s and 1970s, the golden rule for penetrating injuries to the neck was for mandatory surgical exploration. This management protocol emerged from military experience during wartime. ${ }^{12}$ The policy was based on the complex anatomy of the neck, the relative risks involved, and the favourable results obtained with this approach. ${ }^{3}$ In civil settings, with rates of negative neck explorations up to $75 \%,{ }^{4}$ critical retrospective studies in the mid-1970s and 1980s supported a more selective approach to asymptomatic patients. As the structures in zone 1 are difficult to assess clinically, most studies advocate mandatory arteriogram and gastrografin swallow. ${ }^{5}$ Over the past decade there has been a shift from a policy of mandatory exploration of the neck towards selective non-operative management. ${ }^{67}$

The published literature supports insertion of a chest drain in clinically unstable patient with an obvious penetrating chest trauma. This patient sustained an unusual penetrating oesophageal injury in zone I secondary to a transthoracic extrapleural stab wound. He remained haemodynamically stable.

Is it reasonable practice to insert a chest drain without a preliminary CXR in obvious penetrating chest trauma, with a bubbling wound but a clinically stable patient? It remains the practice of the local emergency department to do so.

\section{Authors' affiliations \\ A Jabbar, J V Reynolds, P K Plunkett, St. James' Hospital, Dublin, Ireland \\ Competing interests: none declared}

Correspondence to: Mr A Jabbar, St. James' Hospital, Dublin, Ireland; ajabbar@eircom.net

Accepted for publication 2 September 2004

\section{REFERENCES}

1 Bailey $\mathbf{H}$, ed. Surgery of modern warfare, 3rd ed. Baltimore: William \& Wilkins, 1944:674.

2 Fitchett VH, Pometantz M, Butsch DW, et al. Penetrating wounds of the neck: a military and civilian experience. Arch Surg 1969;99:307-14.

3 Fogelman MJ, Stewart RD. Penetrating wounds of the neck. Am J Surg 1956:91:581-96.

4 Obeid FN, Haddad GS, Horst HM, et al. A critical reappraisal of a mandatory exploration policy for penetrating wounds of the neck. Surg Gynecol Obstet 1985;60:517-22.

5 Biffi WL, Moore EE, Moore FA, et al. Validating the selective management of penetrating neck wounds. Am J Surg 1991;162:517-21.

6 Haim $P$, Ivan S, Uri F. The evolving management of penetrating neck injuries. Isr Med Assoc J, 2001 Apr, 3:31 1-12.

7 Madiba TE, Muckart DJ. Penetrating injuries to the cervical oesophagus: is routine exploration mandatory? Ann R Coll Surg Engl 2003;85: 162-6.

\section{Abdominal pain and dysuria in pregnancy: urinary tract infection or life threatening haemorrhage?}

\section{J Lamyman, H Connor, R Brown}

This report describes the case of a 27 year old woman presenting at 19 weeks' gestation with epigastric pain and dysuria. Initially diagnosed with a urinary tract infection, she re-presented 10 days later with acute abdominal pain and haemoperitoneum. The diagnosis of placenta percreta was not made until laparotomy. This case highlights placenta percreta as a rare but serious complication of pregnancy that may become increasingly frequent as the rates of caesarean delivery rise. Early diagnosis, close monitoring, and prompt surgical management are essential as massive blood loss can occur. This can be challenging, as clinical presentation can be unusual.

\footnotetext{
A
} 27 year old woman presented to the emergency department 19 weeks into her pregnancy with epigastric pain and dysuria. There was no history of vaginal bleeding. Her obstetric history included one termination and six first trimester miscarriages. She had two healthy children, born by caesarean section. Her observations were normal and abdominal examination revealed mild suprapubic tenderness. Urine dipstick was positive for leucocytes and she was diagnosed with a urinary tract infection. Although subsequent microscopy and culture were negative, her symptoms improved following a course of amoxycillin.

She re-presented 10 days later with acute onset, severe epigastric pain radiating to both clavicles. The pain was worse on inspiration and lying flat. On examination, she was pale and distressed, with a pulse of 110/min and blood pressure $115 / 50 \mathrm{mmHg}$. Her abdomen was generally tender with guarding in the epigastric region. Vaginal and speculum examination were unremarkable. Haemoglobin was $93 \mathrm{~g} / \mathrm{l}$, with normal white cell count, urea and electrolytes, liver function and amylase. Arterial blood gas analysis was normal and erect chest revealed no air under the diaphragm.

A transabdominal ultrasound demonstrated a large quantity of fluid in the abdomen and pelvis. Abdominal organs appeared normal, and the fetus was active in adequate liquor. No retroplacental collection was seen, and the ovaries could not be visualised.

She was presumed to have an intra-abdominal bleed, although the source at this point was uncertain. She was admitted under joint surgical and obstetric care. The initial management strategy was conservative. She was closely monitored overnight and remained haemodynamically stable following initial fluid resuscitation. Over the next 6 hours, her symptoms did not settle, and as her haemoglobin dropped to $61 \mathrm{~g} / \mathrm{l}$, she required transfusion. The decision was made to proceed to laparotomy, which revealed 2.5 litres of blood in the abdomen. There was extensive bleeding from the lower segment of the uterus, which had ruptured at the site of a previous caesarean section scar. There was placental penetration through the defect with adherence to the bladder. To control the bleeding, it was necessary to proceed to termination of pregnancy and hysterectomy. The bladder was dissected free and cystoscopy revealed no invasion of the 
mucosal layer. She made a good postoperative recovery. Counselling was arranged to help the patient with her loss and she was discharged from the ward after 7 days.

\section{DISCUSSION}

Placenta percreta is the most extreme form of placenta accreta and is a rare but serious complication of pregnancy. Placenta accreta is abnormal placental attachment or invasion into the myometrium. ${ }^{1}$ Three degrees have been described: true placenta accreta, where villi are adherent to myometrial bed without invasion; placenta increta, where the villi invade the muscle; and placenta percreta, where there is full thickness penetration of the myometrium. ${ }^{2}$

The incidence of placenta accreta increased from 1 per 30739 between 1930 and 1950 to 1 per 7270 in the 1970 s. $^{3}$ The incidence of placenta percreta has been estimated to be around l per 90000 deliveries, ${ }^{4}$ which would equate to around six cases per year in the UK.

Predisposing factors to the development of placenta accreta include: previous caesarean section, uterine curettage, manual removal of the placenta, and placenta praevia. ${ }^{5}$ The increasing incidence of placenta accreta may be due to the increased frequency of caesarean delivery. ${ }^{67}$

The clinical presentation of placenta accreta depends on the degree of placental penetration into the uterus and includes vaginal bleeding, uterine rupture, intra-abdominal haemorrhage, and bladder invasion. ${ }^{7}$ Ultrasound imaging has been used to assess the uterus in pregnancies at risk for placenta accreta. However, the extent of extrauterine involvement could not be consistently demonstrated. ${ }^{18}$ Thus, ultrasound is useful in the acute setting for detection of intraperitoneal fluid, but cannot reliably diagnose placenta percreta.

In retrospect, the urinary tract symptoms experienced by our patient could be considered a "warning" and may have been due to bladder irritation from the invading placenta. However, if no bleeding had occurred at this stage, it is unlikely that ultrasound imaging would have diagnosed the problem.

This case also demonstrates how well a young patient can compensate for substantial blood loss. Rapid decompensation can occur and close monitoring is essential if ongoing haemorrhage is suspected. The presence of placenta accreta increases maternal mortality by $10 \%$. In the report on maternal deaths published in 2001, ${ }^{9}$ two deaths were attributable to placenta accreta. In one of these cases, despite anticipation of haemorrhage and exemplary care, the patient still died from massive blood loss.

Haemoperitoneum and uterine rupture due to placenta percreta usually requires hysterectomy. Conservative surgery has been described and includes localised resection of the placental implantation site, oversewing, blunt dissection, and packing techniques. ${ }^{17}$ However, such techniques have been associated with higher mortality, and their use is probably limited to less extensive accreta, where bleeding is minimal. ${ }^{7}$

Placenta percreta is rare, but as the number of caesarean deliveries increases, so will the number of women at risk. Placenta percreta should be considered in the gravid patient with risk factors for abnormal placental attachment presenting with abdominal pain and evidence of haemorrhage. Early diagnosis and prompt surgical management may reduce maternal mortality.

\section{Authors' affiliations}

M J Lamyman, H Connor, R Brown, Accident and Emergency

Department, St. Mary's Hospital NHS Trust, London, UK

Competing interests: none declared

Correspondence to: Mr M J Lamyman, 8B Merridian Way, Holtye Road, East Grinstead, West Sussex, RH19 3GB, UK; mike.lamyman@ ukgateway.net

Accepted for publication 17 August 2004

\section{REFERENCES}

1 Smith L, Mueller P. Abdominal pain and haemoperitoneum in the gravid patient: A case report of placenta percreta. Am J Emerg Med 1996;14:45-7.

2 Irving FC, Hertig AT. A study of placenta acreta. Surg Gynaecol Obstet 1937;64:178-200.

3 Read JA, Cotton DB, Miller FC. Placenta accreta: Changing clinical aspects and outcome. Obstet Gynaecol 1980;56:31-4.

4 Cario GM, Adler AD, Morris N. Placenta percreta presenting as intraabdominal antepartum haemorrhage. Case report. B J Obstet Gynaecol 1983;90:491-3.

5 Fox H. Placenta acreta 1945 to 1969. Obstet Gynaecol Surv 1972;27:475-90.

6 O'Brien JM, Barton JR, Donaldson ES. The management of placenta percreta: conservative and operative strategies. Am J Obstet Gynaecol 1996; 175: 1632-8.

7 Haynes DI, Smith JHF, Fothergill DJ. A case of placenta increta presenting in the first trimester. J Obstet Gynaecol 2000;20:434-5.

8 Leaphart WL, Schapiro H, Broome J, et al. Placenta previa percreta with bladder invasion. Obstet Gynaecol 1997;89:834-5.

9 Lewis G. Why mothers die: 1997-1999: the fifth report of the confidential enquiries into maternal deaths in the United Kingdom. London: RCOG, 2001.

\section{Tension empyema as a reversible cause for cardiac arrest}

\section{Bramley, H Dowd, C Muwanga}

Empyema is a well recognised complication of pneumonia. ${ }^{1}$ We report a case of pulseless electrical activity (PEA) treated in the emergency department (ED) with intercostal tube drainage based on clinical findings, where a tension empyema was found to be the cause. To our knowledge, this is the first report of actual cardiac arrest from this cause.
A 42 year old man was admitted to the emergency department by ambulance. The paramedic crew had found him in respiratory distress. En route to hospital, he deteriorated to cardiorespiratory arrest. Basic life support was immediately instituted. He had significant previous medical history of type I diabetes mellitus and trisomy 21 . 
His first recorded cardiac rhythm in the resuscitation room was bradycardic pulseless electrical activity (PEA). His airway was secured by endotracheal intubation, and advanced life support protocols were followed, including intravenous epinephrine and atropine. Clinical assessment of the chest revealed a hypoinflated left hemithorax with absent breath sounds, and intubation of the right main bronchus was suspected. The endotracheal tube was withdrawn, but this did not change the clinical findings. Further examination found the trachea to be central and the left hemithorax dull to percussion. A clinical diagnosis of fluid in the left hemithorax was made.

Presuming a haemothorax, a closed needle aspiration of the left chest was attempted using a 14 gauge intravenous cannula and $50 \mathrm{ml}$ syringe in the second intercostal space in the midclavicular line. This revealed a small amount of yellow watery aspirate with no air present. Immediately following this procedure, a left lateral incision was made in the fifth intercostal space along the anterior axillary line in order to insert an intercostal drain. On blunt dissection through the pleura, approximately $500 \mathrm{ml}$ of malodorous pus was released under pressure, followed by an immediate return of spontaneous circulation, with a sinus tachycardia on the cardiac monitor. A central pulse was palpable, and a blood pressure of $120 / 50 \mathrm{mmHg}$ was recorded. A $32 \mathrm{Fr}$ intercostal drain was inserted and secured, which continued to drain a further $400 \mathrm{mls}$ of pus over the next 30 minutes (fig 1), although air was not expelled. The patient was further stabilised and transferred to the intensive therapy unit. Unfortunately, he developed multisystem organ failure and coagulopathy and died 20 hours after admission. A postmortem examination was not carried out, and microbiological samples taken failed to identify any organism.

\section{DISCUSSION}

In all cases of cardiac arrest, potentially reversible causes should be considered. ${ }^{2}$ In this case, it was clinically apparent that there was a problem ventilating the left lung. This was not resolved by repositioning the endotracheal tube, and was not clinically a tension pneumothorax. Drainage was carried out on clinical findings, with immediate effect.

There have been several reports published of tension pyopneumothorax ${ }^{3-5}$ often associated with gastro-oesophageal fistulae, but to our knowledge, this is the first case of cardiac arrest attributed to a tension effect purely from an empyema. The differential diagnoses for this arrest included sepsis and hypoxia, although these could not explain the return of circulation immediately following drainage.

Empyema is defined as an opaque fluid in the pleural space, with the cloudiness due to neutrophils and/or organisms. ${ }^{6}$ It is a well recognised complication of pneumonia, affecting $2-5 \%$ of patients with pneumococcal pneumonia. ${ }^{1}$ Of direct relevance to this case, both mental handicap and diabetes mellitus have been listed as independent risk factors for the development of empyema by the Empyema Subcommittee of the Research Committee of the British Thoracic Society. ${ }^{6}$

The most common presenting feature is malaise, with cough, dyspnoea, pain, and fever also being well recognised. Diagnosis is by aspiration; however, suggestive features on chest radiograph, computed tomography, and ultrasound have been described. Causative organisms can be gram positive or negative, anaerobic or fungal, and in $25 \%$ of cases are mixed (such as Strepococcus milleri plus anaerobes.) Treatment options include combining antibiotics with

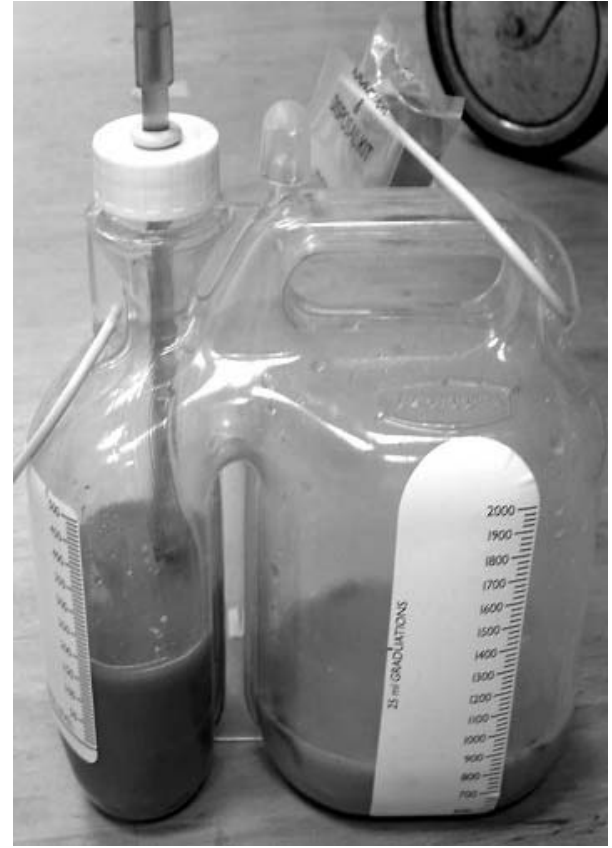

Figure 1 Patient's drainage bottle, showing large quantity of blood and pus.

diagnostic aspiration, repeated aspiration and intercostal tube drainage, or surgical treatment such as rib resection or decortication. One multicentre study has suggested surgical management to be the preferred option. ${ }^{6}$

This case is, to our knowledge, the first documenting cardiac arrest due to a tension empyema and the subsequent acute management. It highlights the importance of searching for reversible causes of cardiac arrest, and describes the use of the intercostal drain as part of resuscitation of a nontraumatic cardiac arrest.

\section{Authors' affiliations}

D Bramley, H Dowd, C Muwanga, Sunderland Royal Hospital, Sunderland, Tyne and Wear, UK

Competing interests: none declared

Correspondence to: Dr H Dowd, Sunderland Royal Hospital, Kayll Road, Sunderland, Tyne and Wear SR 7TP, UK; hugo.dowd@chs. northy.nhs.uk

Accepted for publication 15 October 2004

\section{REFERENCES}

1 Warrell DA, Cox TM, Firth JD. Oxford textbook of medicine, 4th ed. Oxford: Oxford University Press, 2003.

2 Resuscitation Council (UK). Advanced life support course, Provider manual, 4th ed. London: Resuscitation Council (UK) and ERC, 2000.

3 Matsumoto MA, Rockoff SD, Aaron BL. Tension pyopneumothorax. Rare presentation of ruptured Barrett's oesophagus. Chest 1993; 103:1604-6.

4 Whiteman PJ, Wilson MT, Barcay D, et al. Tension pyopneumothorax in a child: a case report. J Emerg Med 2003;24:429-31.

5 Roberts CM, Gelder CM, Goldstraw P, et al. Tension pneumothorax and empyema as a consequence of gastro-pleural fistulae. Respir Med 1990;84:253-4.

6 Ferguson AD, Prescott RJ, Selkon JB, et al. The clinical course and management of thoracic empyema. Q J Med 1996;89:285-9. 


\section{A case of perilymphatic fistula in blunt head injury}

\section{A S Whitelaw, I Young}

Emerg Med J 2005;22:921 . doi: 10.1136/emj.2004.020495

Dizziness is a common symptom following blunt head injury. This is usually attributed to the "post-concussive" syndrome. Here we present a patient whose symptoms following head injury were a result of him having developed a perilymphatic fistula.

A 39 year old man presented to the emergency department having been involved in a motorcycle accident the previous day. He had lost control of his motorcycle while slowing down at a junction and had skidded across a grass verge on his left side. He felt fine afterwards and did not attend the hospital. By the next day, he had developed dizziness and felt unsteady on his feet.

Apart from the patient experiencing dizziness on standing, examination was unremarkable, with normal auroscopy and no focal neurological abnormality. Skull radiographs revealed no vault fracture. Because of his ongoing symptoms, he was admitted for inpatient observation.

By review the following morning, he had developed obvious cerebellar signs. He had past pointing and dysdiodochokinesia, which were worse on the left along with nystagmus on left lateral gaze. Computed tomography scan of his brain was normal.

His cerebellar signs persisted and a magnetic resonance imaging scan the following day was also normal. Due to suspicion of possible labyrinthine injury, an ear, nose and throat (ENT) review was arranged. Both Rinne's and Weber's tests were normal. However, he had a positive fistula test on the left, also weakly positive on the right. Formal audiogram was normal.

A diagnosis of perilymphatic fistula was made and the patient was transferred to the care of the ENT team. He was managed conservatively as an inpatient, with an improvement in his symptoms and signs over a week.

\section{DISCUSSION}

A perilymphatic fistula is an abnormal communication between the middle and inner ear, which allows the escape of perilymphatic fluid into the middle ear. This leakage of fluid leads to the development of vestibular disturbance, with or without hearing loss.

The incidence of dizziness after mild head injury has been reported as being as high as $75 \%$, with the incidence of hearing loss up to $50 \%$. The diagnosis of postconcussive syndrome is frequently attributed to these patients after normal radiological investigation. There have been several reported episodes of patients labelled as postconcussive syndrome being diagnosed with perilymphatic fistula months after a blunt head injury, and requiring surgery because of continuing symptoms.

Perilymphatic fistulae have many causes, including blunt head trauma, Valsalva manoeuvres, vigorous exercise, stapes surgery, and barotraumas. Symptoms and signs include positional vertigo, exercise and Valsalva induced vertigo, positional nystagmus, and hearing loss. The diagnosis should be considered in patients with ataxia and dizziness, with or without hearing loss, in the presence of normal radiological investigations.

The diagnosis is confirmed by a combination of specialist investigations such as an audiogram and a fistula test, performed by applying positive and negative pressure to the intact tympanic membrane. Positive results include the elicitation of nystagmus or the onset of disequilibrium. Electrocochleography can also be informed. This is a method of recording the stimulus related potentials of the cochlea and auditory nerve. ${ }^{1}$

Perilymphatic fistula requires urgent referral to the ENT team. The patient will be managed with bed rest with the head elevated. Surgery is considered if the symptoms progress or fail to settle after $1-2$ weeks.

Although uncommon, perilymphatic fistula must be considered in the differential diagnosis of a patient presenting with dizziness following head injury, especially if associated with hearing loss and normal radiological investigations.

\section{Authors' affiliations \\ A S Whitelaw, I Young, Royal Alexandra Hospital, Paisley, UK \\ Competing interests: none declared}

Correspondence to: Dr I Young, Royal Alexandra Hospital, Corsebar Road, Paisley PA2 9PN, UK; alanswhitelaw@hotmail.com

Accepted for publication 19 October 2004

\section{REFERENCES}

1 Ferraro J, Best LG, Arenberg IK. The use of electrocochleography in the diagnosis, assessment, and monitoring of endolymphatic hydrops. Otolaryngol Clin North Am 1983;16:69-82.

2 Maitland CG. Perilymphatic fistula. Curr Neurol Neurosci Rep 2001;1:486-91.

3 Fitzgerald DC. Persistent dizziness following head trauma and perilymphatic fistula. Arch Phys Med Rehabil 1995;76:1017-20. 